\title{
ETNOBOTANI BAHAN KERAJINAN ANYAMAN DARI HASIL HUTAN BUKAN KAYU OLEH MASYARAKAT SEKITAR HUTAN DESA LANDAU GARONG KABUPATEN MELAWI
}

\author{
(Ethnobotany Woven Craft Materials From Non-Timber forest Products By The Community \\ Around The Village Of Landau Garong Village Melawi District)
}

\author{
Zummais Saroh, Gusti Eva Tavita, Siti Masitoh Kartikawati \\ Fakultas Kehutanan Universitas Tanjungpura, Jalan Imam Bonjol Pontianak 78124 \\ Email: zummais2015@gmail.com
}

\begin{abstract}
Forest is a stretch of land that contains biological natural resources and has the potential to meet the various needs of human life. One benefit is taken immediately from the forest are non-timber forest products in the form of plants for woven handicraft materials. The utilization of non-timber forest products as woven material in the village of Landau Garong has not been documented. This study aims to record and document non-timber forest products that are used by the community around the forest as raw materials for woven crafts and to know the use of plants as traditional woven materials in the Landau Garong Village Pinoh Selatan District Melawi Regency. The study used a survey method with PRA data collection techniques. Data obtained through observation and interviews. The results showed there were 9 plants species that are used, namely sega rattan (Calamus caesius Blume), jempayang rattan (Plectocomia elongata Martiue ex Blume), tajam rattan (Calamus egregius Burret), lingkau bamboo (Gigantochloa hasskarliana), buluh bamboo (Schizostachyum brachycladum), kinyel bamboo (Schizostachyum flexuosum), pandanus (Pandanus tectorius), resam (Dicranopteris linearis), coconut leaves (Cocos nucifera). Produces as many as 16 shapes plaits include bakol, semangang, pemansai, ronjong, ragak, bubu, kelongkang, entungap, rojut, lengkak, layan, timpak, capan, ketupat dan kampel.
\end{abstract}

Keywords: Ethnobotany, Woven Craft, Non-Timber Forest Product, Landau Garong Village

\section{PENDAHULUAN}

Hutan merupakan sumber plasma nutfah yang memiliki potensi untuk memenuhi berbagai kebutuhan manusia seperti papan, pangan hingga obat-obatan. Saat ini hampir semua manusia tergantung pada hutan, baik untuk mengambil manfaatnya secara langsung maupun tidak langsung. Salah satu manfaat yang diambil langsung dari hutan adalah hasil hutan bukan kayu (Simanjuntak et al. 2016). Hasil hutan bukan kayu adalah hasil yang bersumber dari hutan selain kayu seperti tumbuhan bahan baku kerajinan anyaman (Sinaga et al. 2019).

Pemanfaatan tumbuhan hasil hutan bukan kayu sebagai bahan kerajinan anyaman oleh masyarakat dilakukan secara tradisional dan turun temurun (etnobotani). Kerajinan anyaman merupakan salah satu kebudayaan yang dimiliki manusia sejak zaman prasejarah dalam rangka memenuhi kebutuhan dan perlengkapan sehari-hari. Sampai saat ini, kerajinan anyam yang dihasilkan oleh sebagian masyarakat Indonesia memiliki ciri khas dan bentuk 
yang beragam dengan menggunakan bahan yang tersedia di alam baik bambu, pandan, rotan, pandan, resam maupun daun kelapa (Syamsudin, 2015).

Desa Landau Garong merupakan salah satu desa yang ada di Kecamatan Pinoh Selatan Kabupaten Melawi dengan luasan 56000 ha. Penduduk yang mendiami Desa Landau Garong bersuku Dayak Kebahan dan merupakan penduduk asli yang mayoritas pekerjaannya adalah petani. Desa ini memiliki potensi hasil hutan bukan kayu berupa rotan, bambu dan pandan, daun kelapa, dan resam yang cukup tinggi dan tumbuh secara liar. Penduduk di desa ini berpengetahuan tentang pembuatan anyaman dengan memanfaatkan tumbuhan secara tradisional khususnya tumbuhan rotan, bambu, resam, daun kelapa dan pandan secara turun temurun. Pemanfaatan hasil hutan bukan kayu sebagai bahan baku kerajinan anyaman di Desa Landau Garong ini belum terdokumentasikan, oleh karena itu perlu dikaji mengenai etnobotani bahan kerajinan anyaman dari hasil hutan bukan kayu yang berbasis kearifan tradisional di Desa Landau Garong.

Tujuan penelitian ini adalah mendata dan mendokumentasikan hasil hutan bukan kayu yang dimanfaatkan sebagai bahan baku kerajinan anyaman dan untuk mengetahui bentuk pemanfaatan hasil hutan bukan kayu sebagai bahan baku anyaman berbasis tradisional di Desa Landau Garong Kecamatan Pinoh Selatan Kabupaten Melawi.

Manfaat penelitian ini dapat mempelajari kearifan tradisional pemanfaatan tumbuhan rotan, bambu, pandan duri, resam dan daun kelapa sebagai anyaman oleh masyarakat Desa Landau Garong Kecamatan Pinoh Selatan Kabupaten Melawi dan mendokumentasikan jenis-jenis hasil hutan bukan kayu sebagai bahan baku kerajinan anyaman yang telah dilakukan secara turun temurun.

\section{METODE PENELITIAN}

Penelitian ini dilaksanakan di Desa Landau Garong Kecamatan Pinoh Selatan Kabupaten Melawi, dalam waktu \pm 1 bulan. Alat yang digunakan berupa kamera, parang, log book, buku identifikasi bambu (Widjaja, 2001) dan buku identifikasi jenis rotan (atlas rotan jilid 1 dan atlas rotan Indonesia jilid 3). Objek dari penelitian ini adalah masyarakat Desa Landau Garong dan jenis bahan baku kerajinan anyaman. Penelitian ini menggunakan metode survei dengan teknik pengumpulan data menggunakan PRA (Participatory Rural Appraisal). Data diperoleh melalui observasi dan wawancara dibantu dengan tallysheet. Data yang dikumpulkan terdiri dari data primer dan data sekunder. Data primer terdiri dari jenis tumbuhan bahan baku anyaman, dan jenis anyaman. Sedangkan untuk data sekunder terdiri dari letak dan luas, kependudukan, kondisi sosial ekonomi, kondisi sosial budaya masyarakat dan aksesibilitas. Analisis data menggunakan metode deskriptif kualitatif.

\section{HASIL DAN PEMBAHASAN}

Berdasarkan hasil wawancara masyarakat dan identifikasi jenis tumbuhan bahan baku anyaman yang dilaksanakan di Desa Landau Garong Kabupaten Melawi dalam kehidupan sehari - hari mereka memanfaatkan 9 jenis tumbuhan hasil hutan bukan kayu sebagai bahan baku 
untuk membuat anyaman dan menghasilkan sebanyak 16 jenis anyaman. Perolehan data ini menunjukkan bahwa dalam kesehariannya masyarakat Desa Landau Garong memiliki interaksi yang sangat dekat dengan tumbuhan - tumbuhan di sekitarnya.

\section{Jenis Tumbuhan yang Dimanfaatkan} Masyarakat Desa Landau Garong

Jenis tumbuhan yang dimanfaatkan masyarakat Desa Landau Garong untuk membuat anyaman terdapat 9 jenis diantaranya: rotan sega (Calamu scaesius Blume), rotan jempayang (Plectocomia elongata Martiue ex Blume), rotan tajam (Calamus egregius Burret), bambu lingkau (Gigantochloa hasskarliana), bambu buluh (Schizostachyum brachycladum), bambu kinyel (Schizostachyum flexuosum), pandan duri (Pandanus tectorius), resam (Dicranopteris linearis), kelapa (Cocos nucifera). Untuk lebih jelasnya daftar jenis tumbuhan yang digunakan sebagai bahan baku anyaman dapat dilihat pada Tabel 1.

Tabel 1. Jenis Tumbuhan yang Dimanfaatkan Masyarakat Desa Landau Garong Untuk Membuat Kerajinan Anyaman (Types Of Plants Utilized By The Landau Garong Village Community)

\begin{tabular}{|c|c|c|c|c|c|}
\hline No. & Nama Lokal & $\begin{array}{l}\text { Nama } \\
\text { Indonesia }\end{array}$ & Nama Ilmiah & Habitus & Bentang Lahan \\
\hline 1 & Uwi Segak & Rotan Sega & $\begin{array}{l}\text { Calamus caesius } \\
\text { Blume }\end{array}$ & Liana & Dataran rendah \\
\hline 2 & $\begin{array}{l}\text { Uwi } \\
\text { Jempayang }\end{array}$ & $\begin{array}{l}\text { Rotan } \\
\text { bubuai }\end{array}$ & $\begin{array}{l}\text { Plectocomia elongata } \\
\text { Martiue ex Blume }\end{array}$ & Liana & Dataran rendah \\
\hline 3 & Uwi Tajam & Rotan & $\begin{array}{l}\text { Calamus egregius } \\
\text { Burret }\end{array}$ & Liana & $\begin{array}{l}\text { Dataran rendah dan } \\
\text { tepi sungai }\end{array}$ \\
\hline 4 & Buluh & Lemang & $\begin{array}{l}\text { Schizostachyum } \\
\text { brachycladum }\end{array}$ & Bambu & Dataran rendah \\
\hline 5 & Kinyel & Kauayan & $\begin{array}{l}\text { Schizostachyum } \\
\text { flexuosum }\end{array}$ & Bambu & Dataran rendah \\
\hline 6 & Lingkau & Lengka Tali & $\begin{array}{l}\text { Gigantochloa } \\
\text { hasskarliana }\end{array}$ & Bambu & $\begin{array}{l}\text { Tepi sungai dan } \\
\text { dataran rendah }\end{array}$ \\
\hline 7 & Samer & Pandan Duri & Pandanus tectorius & Perdu & Rawa \\
\hline 8 & Daun Nio & Daun Kelapa & Cocos nucifera & Pohon & Dataran rendah \\
\hline 9 & Rosam & Resam & Dicranopteris linearis & Pakis & Dataran rendah \\
\hline
\end{tabular}

Bentuk Pemanfaatan Hasil Hutan Bukan Kayu Sebagai Bahan Baku Anyaman Oleh Masyarakat

Masyarakat Desa Landau Garong memanfaatkan tumbuhan rotan, bambu, pandan duri, resam dan daun kelapa untuk membuat berbagai macam bentuk anyaman untuk menunjang kelangsungan hidupnya. Anyaman yang dihasilkan yaitu sebanyak 16 jenis. Jenis bahan baku yang paling banyak digunakan adalah bambu buluh, rotan sega dan. Untuk lebih jelasnya dapat dilihat pada Gambar 1. 


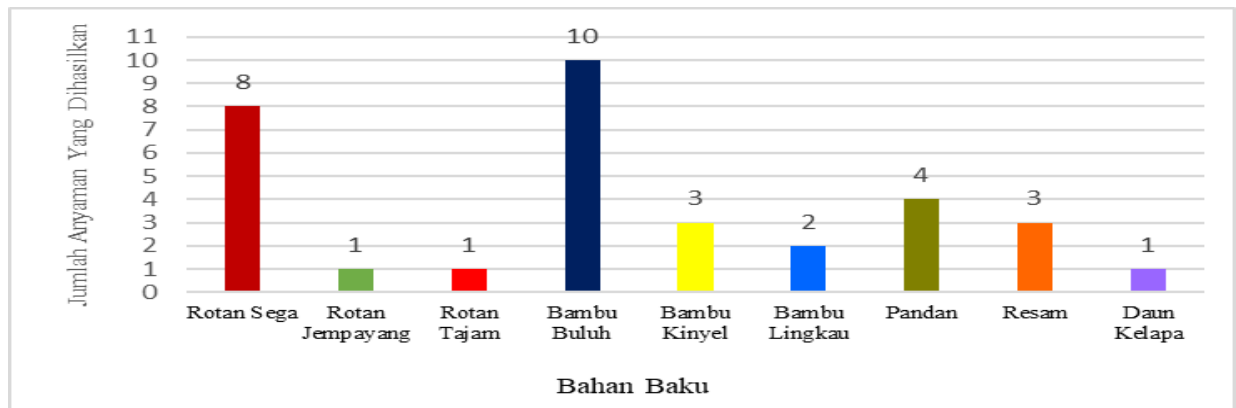

Gambar 1. Jenis Bahan Baku yang Paling Banyak Digunakan (Types of Raw Materials Most Used)

Anyaman yang dihasilkan ada yang terbuat dari satu, dua dan bahkan tiga bahan baku yang berbeda. Anyaman yang dibuat dari tiga bahan baku yaitu bubu. Anyaman yang terbuat dari dua bahan baku meliputi semanggang, ronjong, timpak, capan, kelongkang sasak, kelongkang bukuk, pemansai, ragak, lengkak, rojut dan kampel. Sedangkan anyaman yang terbuat dari satu bahan baku yaitu bakol, entungap, layan dan ketupat dan untuk. Untuk lebih jelasnya dapat dilihat pada Tabel 2.

\section{Tabel 2. Jenis Anyaman yang Dihasilkan (Types Of Woven Produced)}

\begin{tabular}{|c|c|c|c|}
\hline No. & Nama Anyaman & Bahan Baku & Fungsi \\
\hline 1 & Semanggang & $\begin{array}{l}\text { Bambu kinyel, bambu buluh } \\
\text { dan rotan sega }\end{array}$ & $\begin{array}{l}\text { Menangkap ikan, menyimpan dan } \\
\text { mencuci sayur }\end{array}$ \\
\hline 2 & Bakol & Bambu kinyel & Mencuci beras \\
\hline 3 & Ronjong & Bambu kinyel dan rotan sega & $\begin{array}{l}\text { Menyimpan dan membawa ikan } \\
\text { hasil tangkapan mancing, } \\
\text { membawa hasil kebun }\end{array}$ \\
\hline 4 & Timpak & Bambu buluh dan uwi tajam & $\begin{array}{l}\text { Membawa bekal ke ladang dan } \\
\text { untuk mencuci beras }\end{array}$ \\
\hline 5 & Capan & Bambu buluh dan rotan sega & Menampi padi \\
\hline 6 & Bubu & $\begin{array}{l}\text { Bambu buluh, rotan sega dan } \\
\text { resam }\end{array}$ & Menangkap ikan \\
\hline 7 & Kelongkangbukuk & Bambu lingkau dan resam & $\begin{array}{l}\text { Ritual berladang dan adat rumah } \\
\text { baru }\end{array}$ \\
\hline 8 & Kelongkang sasak & Bambu lingkau dan resam & $\begin{array}{l}\text { Ritual berladang dan adat rumah } \\
\text { baru }\end{array}$ \\
\hline 9 & Pemansai & Bambu buluh dan rotan sega & Menangkap ikan \\
\hline 10 & Ragak & Bambu buluh dan rotan sega & $\begin{array}{l}\text { Menyimpan sayuran sebelum dan } \\
\text { setelah dicuci }\end{array}$ \\
\hline 11 & Lengkak & $\begin{array}{l}\text { Bambu buluh, daun pandan } \\
\text { dan rotan sega }\end{array}$ & $\begin{array}{l}\text { Mengangkut dari ladang ke rumah } \\
\text { dan menyimpan padi }\end{array}$ \\
\hline 12 & Rojut & $\begin{array}{l}\text { Bambu buluh, daun pandan } \\
\text { dan rotan sega }\end{array}$ & $\begin{array}{l}\text { Menyimpan beras, memanen padi, } \\
\text { dan menyimpan padi }\end{array}$ \\
\hline 13 & Kampel & Rotan bubuai & $\begin{array}{l}\text { Membawa peralatan berladang, } \\
\text { nebas dan membawa hasil kebun }\end{array}$ \\
\hline 14 & Layan & Daun pandan & $\begin{array}{l}\text { Menjemur padi, alas duduk, ritual } \\
\text { tujuh bulanan }\end{array}$ \\
\hline 15 & Entungap & Daun pandan & $\begin{array}{l}\text { Menyimpan ketan muda yang telah } \\
\text { ditumbuk }\end{array}$ \\
\hline 16 & Ketupat & Daun kelapa & Untuk memasak beras ketan \\
\hline
\end{tabular}




\section{Bagian yang Digunakan}

Masyarakat Desa Landau Garong membuat kerajinan anyaman menggunakan bagian batang muda (bambu kinyel, bambu lingkau dan bambu buluh), batang tua (rotan sega, rotan jempayang, rotan tajam dan resam), daun muda (daun kelapa dan daun pandan), daun tua (daun pandan). Untuk lebih jelasnya dapat dilihat pada Tabel 3 .

Tabel 3. Bagian Tumbuhan yang Digunakan sebagai Bahan Baku Kerajinan Anyaman (Plants Parts Used as Craft Raw Materials)

\begin{tabular}{|c|c|c|c|}
\hline No. & $\begin{array}{l}\text { Bagian yang } \\
\text { Digunakan }\end{array}$ & Jenis Tumbuhan & Jenis Anyaman \\
\hline 1 & Batang Muda & $\begin{array}{l}\text { Bambu kinyel, bambu } \\
\text { lingkau dan bambu buluh }\end{array}$ & $\begin{array}{l}\text { Bakol, kelongkangbukuk, kelongkang } \\
\text { sasak, ragak, pemansai, capan, rojut, } \\
\text { lengkak, timpak, ronjong, semanggang. }\end{array}$ \\
\hline 2 & Batang Tua & $\begin{array}{l}\text { Rotan sega, rotan } \\
\text { jempayang, rotan tajam dan } \\
\text { resam }\end{array}$ & $\begin{array}{l}\text { Ragak, pemansai, kampel, capan, bubu, } \\
\text { rojut, lengkak, timpak, ronjong, } \\
\text { semanggang. }\end{array}$ \\
\hline 3 & Daun Muda & $\begin{array}{l}\text { Daun kelapa dan daun } \\
\text { pandan }\end{array}$ & $\begin{array}{l}\text { Ketupat, entungap manggis, } \\
\text { entungapunang, entungapmanoksobong }\end{array}$ \\
\hline 4 & Daun Tua & Daun pandan & Layan, lengkak, rojut \\
\hline
\end{tabular}

Berdasarkan Tabel 3. bagian batang muda yang digunakan untuk membuat kerajinan anyaman terdapat 3 jenis tumbuhan, batang tua terdapat 4 jenis tumbuhan, daun muda terdapat 2 jenis tumbuhan dan daun tua hanya 1 jenis tumbuhan, sedangkan untuk jenis anyaman yang dihasilkan batang muda menghasilkan 11 jenis anyaman, batang tua 10 jenis anyaman, daun muda 4 jenis anyaman dan daun tua 3 jenis anyaman.

Bentuk Anyaman yang Dihasilkan oleh Masyarakat Desa Landau Garong

Bentuk anyaman yang dihasilkan yaitu sebanyak 16 jenis anyaman. Setiap anyaman mempunyai nilai kearifan lokal tersendiri bagi masyarakat. Satu bentuk anyaman bisa terbuat dari satu atau lebih bahan baku yang berbeda dan memiliki fungsi yang berbeda pula. Anyaman di desa landau garong biasanya dibuat dengan motif meniri (bersilang satu), motif menuai (bersilang ganda) dan tanpa motif. Produk anyaman tersebut tidak diberi pewarna. Pemanfaatan anyaman di Desa Landau Garong sebatas untuk memenuhi keperluan sehari-hari namun belum diperjual belikan. Menurut Rahman dan Mutmainah (2015), motif anyaman yang ada di Desa Kalinganyar Pulau Kangean terdiri dari motif kembang jeruk, udan iris, kepang walik, seruni, dan motif miring. Menurut Nuwa (2018), masyarakat Desa Menteng Kabupaten Palangkaraya memanfaatkan temulawak sebagai pewarna alami dalam pembuatan anyaman. Untuk lebih jelasnya dapat dilihat pada Gambar 2. 


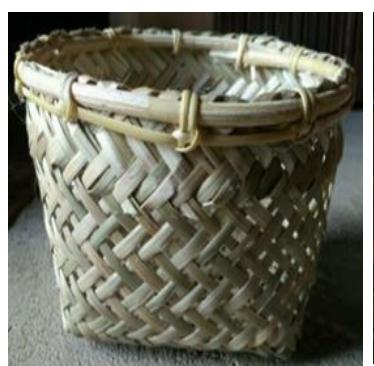

a

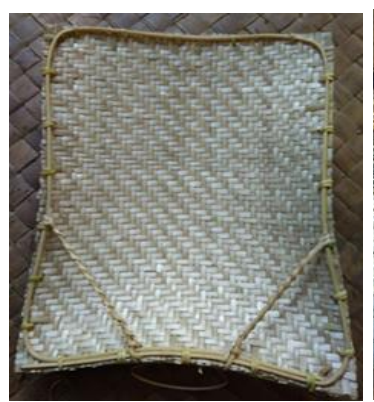

e

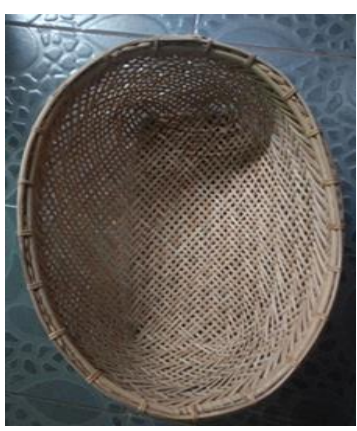

$\mathrm{i}$

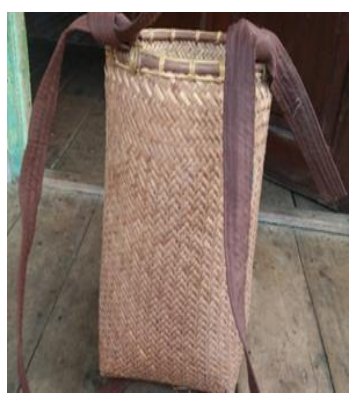

$\mathrm{m}$

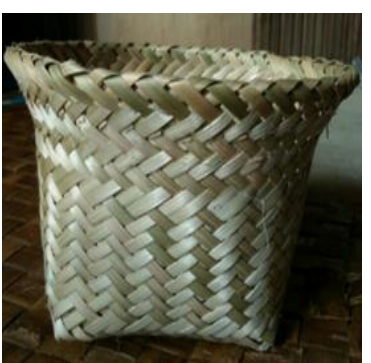

b

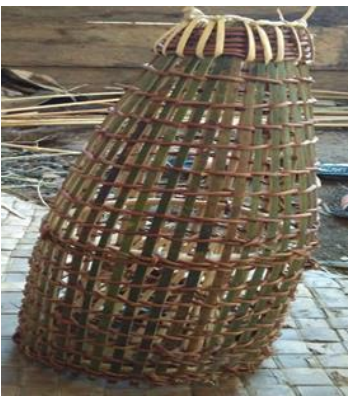

f

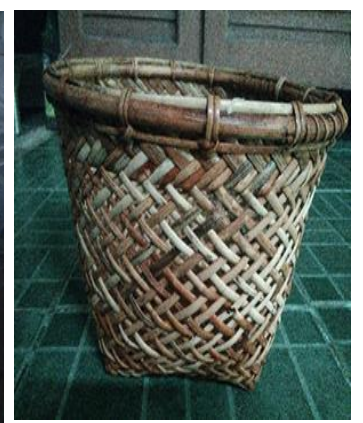

j

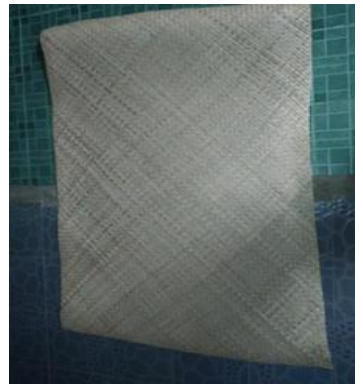

$\mathrm{n}$

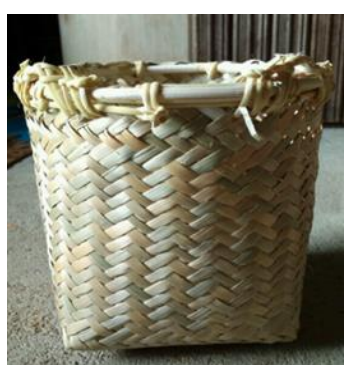

c

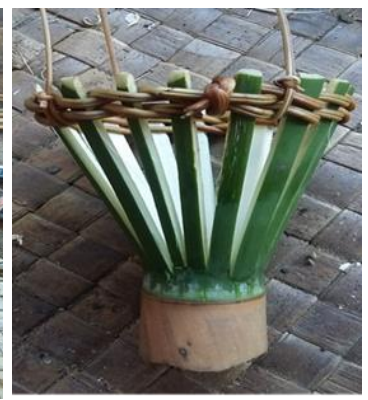

g

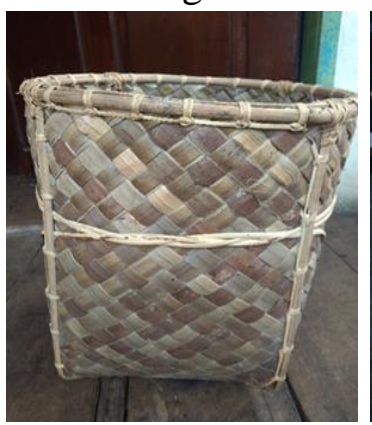

k

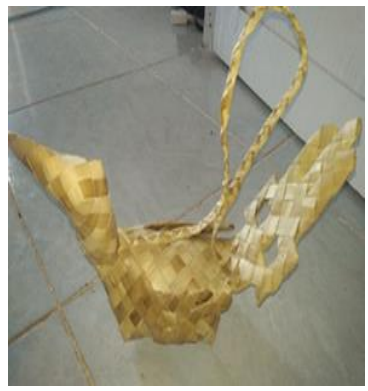

O

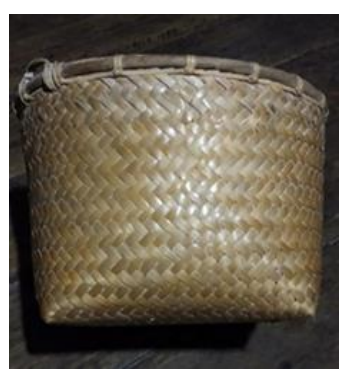

d

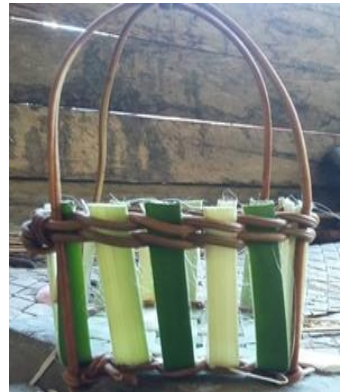

h

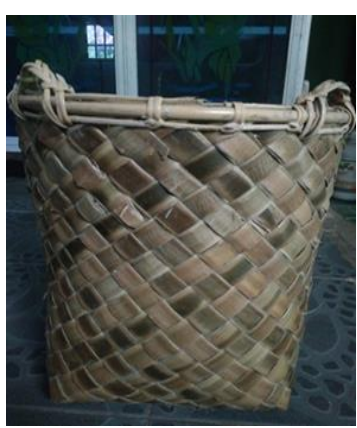

1

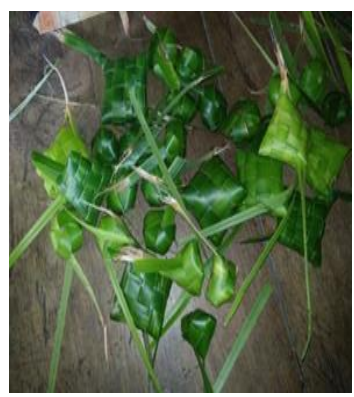

$\mathrm{p}$

Gambar 2. Bentuk Anyaman yang Dihasilkan a. Semanggang, b. Bakol, c. Ronjong, d. Timpak, e. Capan, f. Bubu, g. Kelongkang Bukuk, h. Kelongkang Sasak, i. Pemansai, j. Ragak, k. Lengkak, l. Rojut, m. Kampel, n. Layan, o. Entungap, p. Ketupat (Form of Matting Produced a. Semanggang, b. Bakol, c. Ronjong, d. Timpak, e. Capan, f. Bubu, g. Kelongkang Bukuk, h. Kelongkang Sasak, i. Pemansai, j. Ragak, k. Lengkak, l. Rojut, m. Kampel, n. Layan, o. Entungap, p. Ketupat). 
Ciri, fungsi dan cara penggunaan dari setiap jenis anyaman pada Gambar 2 adalah sebagai berikut:

\section{a. Semanggang}

Semanggang terbuat dari bambu kinyel atau bambu buluh yang dipadukan dengan rotan sega sebagai kerangkanya, berbentuk bulat agak panjang dengan ukuran $20 \mathrm{~cm}$ x $15 \mathrm{~cm}$ dan dianyam menuai (bersilang ganda). Anyaman semanggang biasa dibuat oleh ibu-ibu rumah tangga pada saat waktu luang. Semanggang biasa digunakan masyarakat untuk menangkap ikan disungai dan diparit sawah khususnya anak kecil, dan bisa juga digunakan untuk menyimpan sayur dan menyimpan bawang dan bumbu dapur. Cara menggunakan semanggang juga hampir sama dengan pemansai yaitu pegang kedua sisinya.

\section{b. Bakol}

Bakol terbuat dari bambu kinyel biasa dibuat dengan diameter $30 \mathrm{~cm}-90 \mathrm{~cm}$. Bentuknya bulat melebar pada bagian atasnya dan pada bagian bawahnya berbentuk segi empat dianyam dengan bilah meniri (bersilang satu). Bakol biasanya digunakan masyarakat untuk mencuci beras, ketan dan biji selasih. Cara menggunakan bakol yaitu pegang sisi kiri dan sisi kanannya.

\section{c. Ronjong}

Ronjong terbuat dari bambu kinyel dan rotan sega sebagai kerangkanya berbentuk bulat memanjang ke atas, biasanya dibuat dengan ukuran $30 \mathrm{~cm}-$ $60 \mathrm{~cm}$, dianyam dengan bilah meniri (bersilang satu). Ronjong digunakan bapak-bapak di Desa Landau Garong untuk menyimpan tangkapan ikan dari hasil mancing dan digunakan para gadis dan ibu-ibu saat kegiatan mansai (mencari ikan disungai), menyimpan pisok untuk menoreh. Cara menggunakan ronjong adalah kaitkan tali dibahu sebelah kiri atau kanan.

\section{d. Timpak}

Timpak terbuat dari bambu buluh dan Rotan tajam sebagai kerangkanya, timpak berbentuk bulat, dibuat dengan ukuran yang cukup besar yaitu berdiameter mencapai $100 \mathrm{~cm}$. Anyaman timpak biasa dibuat oleh ibu-ibu dengan bilah meniri (bersilang satu). Timpak digunakan masyarakat untuk menyimpan bekal dan barang-barang yang akan dibawa ke ladang dan kebun, timpak dapat juga digunakan untuk mencuci beras pulut yang digunakan untuk membuat lemang. Cara menggunakan timpak yaitu di kaitkan tali dibahu atau dikepala, untuk mencuci beras pulut cara menggunakannya yaitu pegang sisi kiri dan kananya lalu celupkan timpak tersebut ke dalam air.

\section{e. Capan}

Capan terbuat dari bambu buluh dan rotan sega sebagai kerangkanya, berbeda dengan alat anyaman penampi beras didaerah lain anyaman penampi beras di Desa Landau Garong ini berbentuk segi empat yang di desain khusus oleh nenek moyang terdahulu agar memudahkan dalam penggunaannya, capan diberi kerangka dengan rotan sega yang masih bulat agar lebih kokoh. Capan digunakan 
masyarakat Desa Landau Garong untuk menampi padi atau beras. Cara menggunakan capan yaitu tuangkan beras atau padi pada capan kemudian pegang kedua sisinya lalu naik turunkan capan. Di Desa Babane Kabupaten Bengkayang capan disebut nyero. Nyero berbentuk bulat seperti lingkaran Nyero merupakan alat yang digunakan penampi beras dan biji-biji lainnya seperti jagung dan kacang untuk menghilangkan kulit ari biji (Usman 2019).

\section{f. $B u b u$}

$B u b u$ terbuat dari bambu buluh, resam dan rotan sega. Anyaman bubu biasa dibuat oleh bapak-bapak di Desa Landau Garong yang dikerjakan pada saat malam hari karena pada waktu siang hari mereka gunakan untuk bekerja sebagai petani karet dan berladang. Bubu biasanya dibuat dengan jumlah bilah yang ganjil karena dipercaya jika $b u b u$ dibuat dengan jumlah bilah yang genap ikan tidak akan masuk ke dalam bubu tersebut. Bubu dibuat berbentuk bulat memanjang dan mengerucut pada bagian atasnya, di dalamnya memiliki ijab yang berfungsi sebagai pintu masuk dan perangkap ikan agar tidak dapat lolos keluar lagi di dalam bubu biasanya diisi kelapa sawit, telur semut merah dan tempoyak sebagai umpan. Bubu yang berukuran kecil dipasang di parit pematang sawah dan bubu yang berukuran besar dipasang di sungai. Bubu terbuat dari bambu buluh, rotan segak dan resam.

\section{g. Kelongkang bukuk}

Kelongkang bukuk digunakan masyarakat sebagai ritual adat yaitu untuk adat berladang, dan adat rumah baru. Kelongkang bukuk terbuat dari bambu lingkau dan resam, kelongkang bukuk berbentuk panjang dan melebar ke atas. Cara menggunakan kelongkang bukuk yaitu dengan mengisi kelongkang tersebut dengan berbagai macam sesaji berupa darah hewan, kaki dan kepala ayam, paku, serabi topong tabar, lempin, daun mali-mali dan beras kuning kemudian kelongkang digantung di penyangga rumah.

\section{h. Kelongkang Sasak}

Ukuran kelongkang sasak lebih besar dari pada kelongkang bukuk. Kelongkang sasak biasanya digunakan masyarakat untuk ritual adat berladang, dan adat pindah rumah baru sama halnya dengan kelongkang bukuk. Kelongkang sasak terbuat dari bambu lingkau dan resam. Kelongkang sasak berbentuk segi empat. Cara menggunakannya juga sama dengan kelongkang bukuk yaitu dengan mengisi kelongkang tersebut dengan berbagai macam sesaji berupa darah hewan, kaki dan kepala ayam, paku, serabi topong tabar, lempin, daun malimali dan beras kuning kemudian kelongkang digantung di penyangga rumah.

\section{i. Pemansai}

Pemansai digunakan masyarakat Desa Landau Garong khususnya perempuan untuk menangkap ikan di sungai atau di pematang parit sawah. Pemansai terbuat dari bambu buluh dan rotan segak, pemansai berbentuk memanjang. Cara menggunakan pemansai yaitu pegang kedua sisinya yaitu sisi kiri dan sisi kanan dan biasanya di bentang sesuai 
arah yang ada ikannya dan besarnya ukuran sungai dan parit sawah.

\section{j. Ragak}

Ragak berfungsi untuk menyimpan sayur sebelum dan sesudah dicuci. Ragak terbuat dari bambu buluh dan rotan segak, ragak berbentuk bulat dan pada bagian atas agak melebar. Cara menggunakan ragak yaitu pegang bagian sisinya.

\section{k. Lengkak}

Lengkak berfungsi untuk menyimpan bekal atau barang ke ladang dan kebun, lengkak juga digunakan untuk menyimpan padi setelah dipanen dan menyimpan beras setelah ditumbuk. Lengkak terbuat dari bambu buluh dan daun pandan berbentuk bulat panjang. Cara menggunakan lengkak sama dengan timpak yaitu kaitkan tali dibahu dan dikepala.

\section{Rojut}

Rojut berfungsi untuk menyimpan beras yang sudah ditumbuk dan menyimpan padi pada saat pemanenan. Rojut terbuat dari bambu buluh dan daun pandan, rojut berbentuk bulat memanjang, bentuknya juga hampir sama dengan timpak. Cara menggunakan rojut sama dengan timpak, lengkak, ronjong yaitu kaitkan tali dibahu dan dikepala.

\section{m. Kampel}

Kampel berfungsi untuk tempat membawa peralatan untuk berladang, nebas, membawa hasil kebun dan lainlain. Kampel terbuat dari uwi jempayang. Kampel bentuknya bulat memanjang seperti ronjong tetapi ukurannya lebih besar dibandingkan ronjong. Disisi kiri kanannya dipasang tali untuk membawanya. Cara menggunakan Kampel yaitu talinya di ranselkan di kedua bahu seperti membawa tas ransel.

\section{n. Layan}

Layan terbuat dari daun pandan, dengan bentuk persegi panjang. Layan berfungsi untuk menjemur padi, ritual tujuh bulanan, dan alas tempat duduk. Cara menggunakan layan dalam acara tujuh bulanan yaitu meletakan sejumlah barang seperti tempayan, buah kelapa, buah asam, nangka, terasi dan cabe lalu barang-barang tersebut digulung di dalam layan lalu dibacai mantra kemudian layan diangkat ke atas lalu dihempas ke bawah, ritual ini dilakukan untuk anak pertama yang dipercaya oleh masyarakat Dayak Kebahan Desa Landau Garong agar anakyang lahir selamat dan sehat walafiat. Untuk menjemur padi dan alas duduk dilakukan dengan cara menghamparkan layan di atas tanah atau lantai rumah.

\section{o. Entungap}

Entungap terbuat dari daun pandan yang masih muda. Entungap dibuat dengan berbagai macam bentuk sesuai yang diinginkan, entungap biasanya berbentuk seperti buah manggis, udang dan ayam, entungap biasa digunakan untuk menyimpan ompin (ketan muda yang disangrai kemudian di tumbuk lalu ditampi dan dicampur dengan parutan kelapa) agar menambah aroma pada ketan.

\section{p. Ketupat}

Ketupat terbuat dari daun kelapa, ketupat memiliki banyak bentuk ada yang bulat, lonjong, ada yang seperti bawang, 
seperti layang-layang, dll. masyarakat biasa membuat ketupat dalam acara melabo (makan bersama) dan pada saat hari raya.

\section{KESIMPULAN}

Berdasarkan hasil penelitian tentang etnobotani bahan kerajinan anyaman dari hasil hutan bukan kayu oleh masyarakat sekitar hutan Desa Landau Garong Kabupaten Melawi, dapat disimpulkan bahwa:

1. Terdapat 9 jenis tumbuhan yang digunakan masyarakat Desa Landau Garong Kabupaten Melawi sebagai bahan dasar dalam pembuatan kerajinan anyaman. Jenis - jenis tumbuhan tersebut yaitu: rotan sega (Calamus caesius Blume), Rotan Jempayang (Plectocomia elongata Martiue ex Blume), Rotan Tajam (Calamus egregius Burret), Bambu Lingkau

(Gigantochloa hasskarliana), Bambu Buluh (Schizostachyum brachycladum), Bambu Kinyel (Schizostachyum flexuosum), Pandan Duri (Pandanus tectorius), Resam (Dicranopteris linearis), Daun Kelapa (Cocos nucifera).

2. Masyarakat Desa Landau Garong Kabupaten Melawi memanfaatkan tumbuhan rotan, bambu, pandan dan daun kelapa sebagai bahan baku untuk membuat anyaman berupa peralatan rumah tangga seperti bakol, semangang, pemansai, ronjong, ragak, bubu, kelongkang, entungap, rojut, lengkak, layan, timpak, capan, ketupat dan kampel.

\section{SARAN}

1. Masyarakat Desa Landau Garong perlu melakukan pembudidayaan untuk jenis bambu buluh dan rotan sega karena merupakan jenis yang paling banyak digunakan agar keberadaannya tetap lestari.

2. Masyarakat Desa Landau Garong diharapkan dapat mengenalkan produk kerajinan tangan milik mereka kepada masyarakat di luar Desa Landau Garong.

\section{DAFTAR PUSTAKA}

Jasni, Damayanti R, Kalima T. 2012. Atlas Rotan Indonesia Jilid 1. Pusat Penelitian dan Pengembangan Keteknikan Kehutanan dan Pengolahan Hasil Hutan, Bogor.

Nuwa, Putir PE, Pisi B. 2018. Temulawak Sebagai Pewarna Dalam Desain Produk Anyaman Rotan Di Kelurahan Menteng Kota Palangkaraya. Jurnal Hutan Tropika 13(2):87-93

Rahman K, Mutmainah S. 2015. Pengembangan Desain Kerajinan Anyam Bambu Desa Kalinganyar Pulau Kangean. Jurnal Pendidikan Seni Rupa 3(3):111117

Simanjuntak N, Idham M, Ardian H. 2016. Pemanfaatan Rotan Sebagai Bahan Kerajinan Anyaman Di Desa Sedahan Jaya Kecamatan Sukadana Kabupaten Kayong Utara. Jurnal Hutan Lestari 4(3):344-351

Sinaga M.F, AM Iskandar, Thamrin E. 2019. Pemanfaatan Bambu Oleh Masyarakat Pengrajin Desa Menyabo Kecamatan Tayan 
Kabupaten Sanggau. Jurnal Hutan Lestari 7(3):1235-1244

Syamsudin ND. 2015. Kerajinan Anyam. Widyaiswara PPPPTK Seni dan Budaya Yogyakarta.

Usman. 2019. Pemanfaatan Bambu Oleh Masyarakat Desa Babane Kecamatan Samalantan
Kabupaten Bengkayang. Jurnal Hutan Lestari 7(2):655-667

Widjaja, E.A. 2001. Identikit Jenis Jenis Bambu di Jawa (Identity Kits forthe bamboo species in Java). Pusat Penelitian dan Pengembangan Biologi - LIPI. Balai Penelitian Botani. Bogor. Indonesia. $101 \mathrm{pp}$. 